\title{
CANCER IN DIALYSIS PATIENTS
}

DOI: 10.36740/WLek202009232

\author{
Monika Wieliczko, Michał Pyrża, Jolanta Małyszko \\ DEPARTMENT OF NEPHROLOGY, DIALYSIS AND INTERNAL DISEASE, MEDICAL UNIVERSITY OF WARSAW, WARSAW, POLAND
}

\begin{abstract}
Cancer in dialysis patients is a common problem and is one of the most common reasons of mordibity and mortality in developed countries. An impaired renal function leads to the accumulation in the blood products of nitrogen transformation, which negatively affect organ function, especially the immune system. The Standardized Cancer Incidence is higher in patients with end-stage kidney failure than in the general population and reaches 1,18-1,42. The cancer risk is three times higher in dialysis patients over age 65 years and is more common among hemodialysis than peritoneal dialysis patients. The most common type of cancer occurring in this group of patients is urinary tract cancer which often develops on the basis of acquired cysts and in patients previously treated with cyclophosphamide. Nonetheless, patients with kidney problems are not regularly tested for these diseases and the only group that is screened for cancer are patients tested for kidney transplantation. Some problems in this topic are briefly presented in this article.
\end{abstract}

KEY WORDS: chronic kidney disease, malignancy, standardized cancer incidence, life expectancy

Wiad Lek. 2020;73(9 p. II):2068-2072

\section{INTRODUCTION}

Cancer is one of the most common reason of mordibity and mortality in developed countries, and Chronic Kidney Disease (CKD), which affects $5-15 \%$ of the population in these countries, appears to be an additional risk factor. An impaired renal function leads to the accumulation in the blood products of nitrogen transformation, which negatively affect organ function, especially the immune system and include both immunoactivation and immunosuppression disorders.

CKD also leads to the renin-angiotensin-aldosterone system (RAAS) activation [1,2] and endothelial disorders [3], what can increase the risk of cancer. The uremic toxins such as indoxyl sulfate and p-crezyl sulfate can additionally impair DNA repairing [4-6].

The abnormal immunoactivation is multifactorial, mainly affects monocytes, increased synthesis of proinflammatory cytokines such as interleukin 1 (IL-1), IL-6, tumor necrosis factor (TNF) and chemokines [7-8]. This immunoactivation is additionally stimulated by the increased gut permeability, intestinal dysbiosis [8-9], exogenous factors such as potential dialysis access contamination (catheters and not native fistulas) and dialysis membranes biocompatibility [10].

The immunosuppression relates to reduced function of $\mathrm{T}$ and B lymphocytes, which additional affects the accelerated body aging $[7,9,11-12]$.

\section{EPIDEMIOLOGY}

The risk of cancer increases with the CKD progression and, it is estimated, to be the largest in the end-stage of the disease (endstage kidney disease - ESKD) [13-17]. We do not have standardized global statistics, data comes from different regions, in which there are additional risk factors for cancer development.
Nevetheless, all data inform us of a generally higher risk of cancer in CKD patients, especially in the end-stage of the disease, resulting in an overall standardized cancer incidence (SIR) 1.18-1.42 [19] (regional differences: Australia SIR 1,35, Denmark SIR 1,6). The cancer risk is three times higher in dialysis patients over age 65 years and is more common among hemodialysis than peritoneal dialysis patients [2021]. Some cancer - especially urinary tract - occur in dialysis patients much more often than others (below).

The additional risk factors in dialysis patients are: acquired renal cysts [22], prolonged analgesic abuse (acetaminophen and non-aspirin nonsteroidal antiinflammatory drugs: $\mathrm{RR}$ - relative risk - 1,28 i 1,25 respectively), prolonged oral cyclophosphamide ( $>36 \mathrm{~g}), \mathrm{HBV}, \mathrm{HCV}$ and HPV infections (Table 1).

\section{THE MOST COMMON CANCERS IN CKD PATIENTS BEFORE DIALYSIS}

Data on the incidence of cancer at particular CKD stages and their types are scarce and some studies describe conflicting data [25-32]. This is due to many factors, including the presence of nonspecific early symptoms, no clear recommendations for screening in this patient group or different age groups qualified for studies. The three largest studies on this topic from Sweden, USA and Korea [13,25-26] obtained the following results:

1. the highest risk of any cancer was found in patients with $\mathrm{eGFR} \geq 105 \mathrm{ml} / \mathrm{min}[13,25-26]$;

2. the highest risk of developing colorectal and lung cancers [13] were found in patients with eGFR $\geq 105$ $\mathrm{ml} / \mathrm{min}$, which may, however, result from methodological errors (frequent cachexia in these patients overestimated eGFR); 
Table 1. Additional risk factors of cancer in dialysis patients

\begin{tabular}{cc}
\hline Risk factor & Type of cancer \\
\hline Aquired renal cysts & RCC - renal cell carcinoma \\
Prolonged analgesic abuse & $\begin{array}{c}\text { Cancinoma of renal pelvis } \\
\text { Cancinoma of the bladder } \\
\text { Cancinoma of the ureter }\end{array}$ \\
\hline Cyclophosphamide & Cancinoma of the bladder \\
\hline HBV $\mathrm{HCV}$ & HCC - hepatocellular carcinoma \\
\hline HPV & Carcinoma of the cervix \\
\hline
\end{tabular}

Table 2. SIR in hemodialysis patients general and for some specific sites (Europe, USA, Australia/New Zealand, Denmark, Taiwan Hong-Kong) [50].

\begin{tabular}{ccc}
\hline Cancer & SIR (about) [33] & SIR (regional differences) [50] \\
\hline Kidney & 4,03 & $2,8-12,28$ \\
\hline Bladder & 1,57 & $1,5-1.57$ \\
\hline Breast & 1,42 & $0,8-1,65$ \\
\hline non-Hodgkin lymphoma & 1,37 & $0,6-1,7$ \\
\hline Lung & 1,28 & $0,9-1,5$ \\
\hline Liver & & $1,2-2$ \\
\hline Thyroid/other endocrine & $1,9-5,9$ \\
\hline Tongue & & $1,2-4,21$ \\
\hline Cervix & & $2,5-4$ \\
\hline Multiple myeloma & & $2,5-5,2$ \\
\hline Colorectal & 1,27 & $0,9-1,53$ \\
\hline Prostate & 1,06 & $0,27-1,2$
\end{tabular}

3. the cancer risk is different at different CKD stages, however, in people with reduced GFR, is the highest in the end period and appears to increase as the disease progresses;

4. it has been shown to increase non-melanoma skin cancer, urinary tract, prostate, blood cancers with eGFR decrease; the risk of breast cancer in women has not increased;

5. the risk of developing any cancer was similar in both sexes and the highest between 40 a 49 years old [13];

6. the lowest risk of cancer is difficult to determine because, in the above-mentioned studies, conflicting data were obtained (eGFR 90-104 $\mathrm{ml} / \mathrm{min}$ vs 60-89 $\mathrm{ml} / \mathrm{min}$ vs $45-59 \mathrm{ml} / \mathrm{min}$ respectively).

\section{THE MOST COMMON CANCERS IN DIALYSIS PATIENTS}

The risk of developing some cancers increases in the endstage CKD compared to the general population. This risk mainly concerns urinary tract cancers (kidney, bladder), liver, thyroid, cervix, tongue as well as multiple myeloma and non-Hodgkin lymphoma $[18,22]$.

Other cancers usually occur by population frequency (regional differences are described) [18-22] (Table 2).

\section{SURVIVAL OF PATIENTS WITH CANCER ON DIALYSIS}

The 3-year survival of dialysis patients without cancer varies depending on the treatment method: the highest among live donor renal recipients and the lowest among hemodialysis patients (91\% vs $57 \%$ ) and is lower than in comparative population groups (98\%). It is estimated that the survival of 50 -year- old hemodialysed man is 7.7 years and a man of a similar age in the general population -27.7 years [33-34]. Even lower survival is recorded among dialysis patients without cancer - patients with cancer have a slightly higher mortality risk and the risk increases with the time of dialysis. One study showed the higher cancer risk in patients on dialysis for more than 3 years ( $9 v s$ 6,5/1000 patient-years) [35]. Despite the higher risk of death due to cancer, cardiovascular diseases are still the main cause of death in this patients group (about $50 \%$ vs 4\%; 38 vs $7 / 1000$ patient-years) [36-38].

\section{THE DIAGNOSTIC AND THERAPEUTIC PROBLEMS}

As mentioned above, there are no harmonized recommendations for cancer screening in CKD patients although recommendations for early detection of cancer are routinely 
Table 3. Unreliable results of screening tests (NSE - neuron-specific enolase; SCC - squamous carcinoma cell antigen; (EA - carcinoembryonic antigen))

\begin{tabular}{cc}
\hline Tumor markers & Usefulness in diagnostics \\
\hline Fecal occult blood testing & High false-positive rate \\
Mammography & $\begin{array}{c}\text { High false-positive rate } \\
\text { Higher rate of microcalcifications } \\
\text { Higher rate of adenomas } \\
\text { Higher rate of dense-breast tissue }\end{array}$ \\
Tumor markers & High false-positive rate \\
& (Ca-125 especially in peritoneal dialysis patients \\
& SCC \\
& CEA) \\
\hline
\end{tabular}

used in the general population. The only recommendations in this topic were specified for patients qualified for kidney transplantation. In each case, starting diagnostics, especially in the early asymptomatic cases, it is necessary to answer the question what benefits the object gained from making the diagnosis and what treatment can be implemented considering the patient's age, general condition and comorbidities. Among the benefits we should definitely take into account the extension of life and improvement its quality. Taking into account the estimated survival of such a patient, the topic is still valid. The American Society of Nephrology (2012) recommend against routine cancer screening in dialysis patients, because of limited life expectancy [39]. The recommendations are based on population studies in which benefits of screening were only seen with an estimated minimum 10-years survival time (e.g. breast and colorectal cancers). Another problem in the CKD population, especially in dialysis patients, are unreliable screening tests results. This applies especially for tumor markers, which, in most cases, are macromolecules ( 3400 $\mathrm{kD}-5000 \mathrm{kD}$ ) ineffectively removed during hemodialysis [36-38] except AFP (alpha-fetoprotein) and PSA, whose specificity is high. The role of other antigens in cancer diagnosis is unclear in this patients group (Table 3) [4045]. Nonetheless, it is wrong to routinely neglect or refuse cancer diagnosis in people with CKD when it is necessary to perform tests using contrast media. Each case requires a separate, precise discussion with the patient and make a joint decision.

A therapy is a separate problem. In patients with impaired renal function many adverse outcomes of surgical treatment of colorectal and lung cancers, e.g. the need for re-intubation, prolonged ventilation, higher rate tissue infection, sepsis, pneumonia and 63\% higher mortality risk in dialysis patients compared to general population are demonstrated [46]. In addition to surgical problems, chemotherapy is also difficult. Many drug programs are not available to patients with impaired renal function in predialysis period or even in the initial CKD stages. The available medicines require dose adjustment appropriate to eGFR, which carries the risk of giving too little or too much drug. The influence of modern oncological therapies on the kidneys is also important. It may affect both a deterioration their function and cause a new disease in them. Patients on dialysis with cancer are treated essential as well as the general population, doses of chemotherapeutic agents need additional adjustment, taking into account their removal during dialysis procedures. However, there is still no convincing data on the oncological treatment results in this group of patients.

\section{CONCLUSION}

Cancer significantly reduce survival in the general population and somewhat in the dialysis patient population. There are more common than in the general population. In this group of patients may occur any cancer, however, urinary tract cancers have a significant advantage. There is still a discussion about the screening problem in dialysis patients. It is calculated that the expected benefit of such costly proceedings is to extend life by a maximum of 5 days and reduce the ESKD mortality rate by 0.02 percent [47-48]. Most of the studies in this topic, however, ended about 10 years ago and today this data may be unreliable, especially, mortality in the dialyzed patient group is today reduced (2001-2016 up to 29\% reduction) [49]. Each case requires individual diagnosis and treatment. However, it appears that studies assessing the risk, benefits and costs of diagnostics for specific cancers are needed in large patient group. Screening procedures proposed by some researchers in the dialysis patients would only concern candidates for kidney transplantation and those whose estimated survival time is longer ten 10 year [33]. But there are no validated scoring systems to estimate the 10-year survival of dialysis patients (calculators for the general population are available online) which would greatly facilitate diagnostic and therapeutic decision. Although the data from years ago showed that a 20 -year-old patient with kidney cancer and the estimated survival time of 25 years after cancer treatment will extend the life of about 1.6 years but a 58-year-old patient by only 4-5 days, there is no current data taking into account today's reality [50]. Screening for urinary tract cancer rather should be done regularly especially as the number of acquired kidney cysts increases as the time of dialysis increases and the cysts are the risk factor for kidney cancer. We also believe that screening in 
the remaining groups of patients with reduced glomerular filtration in a predialysis period should be conducted as in the general population.

\section{REFERENCES}

1. Viazzi F, Bonino B, Cappadona F, Pontremoli R. Renin-angiotensinaldosterone system blockade in chronic kidney disease: current strategies and a look ahead. Intern Emerg Med 2016;11:627-635.

2. Wegman-Ostrosky T, Soto-Reyes E, Vidal-Millan S, Sanchez- Corona J. The renin-angiotensin system meets the hallmarks of cancer. J Renin Angiotensin Aldosterone Syst 2015;16: 227-233.

3. Tomiyama H, Yamashina A. Clinical Considerations for the as- sociation between vascular damage and chronic kidney disease. Pulse (Basel) 2014;2:81-94.

4. Menck CF, Munford V. DNA repair diseases: What do they tell us about cancer and aging? Genet Mol Biol 2014;37(Suppl):220-233.

5. Sun CY, Chang SC, Wu MS. Suppression of Klotho expression by proteinbound uremic toxins is associated with increased DNA methyltransferase expression and DNA hypermethylation. Kidney Int 2012;81:640-650.

6. Cheng H, Wang L, Mollica M, Re AT, Wu S, Zuo L. Nitric oxide in cancer metastasis. Cancer Lett 2014;353:1-7.

7. Kooman JP, Kotanko P, Schols AMW, Shiels PG. Chronic kidney disease and premature ageing. Nat Rev Nephrol. 2014;10:732-742.

8. Sato Y, Yanagita M. Immunology of the aging kidney. Nat Rev Nephrol. 2019;15:625-640.

9. EbertT, PawelzikSC, Witasp A, et al. Inflammation and premature aging in chronic kidney disease. Toxins 2020;12:27-248.

10. Kooman JP, Dekker MJ, Usvyat LA, et al. Inflammation and premature aging in advanced chronic kidney disease. Am J Physiol Ren Physiol. 2017;313:F938-F950.

11. Cuadrado A, Manda G, Hassan A, et al. Transcription factor NRF2 as a therapeutic target for chronic kidney disease: a system medicine approach. Pharmacy Rev. 2018;70:348-383.

12. Carrero JJ, Stenvinkel P. Inflammation in end-stage renal disease-- what have we learned in 10 years? Semin Dial 2010;23:498-509.

13. Hong Xu, Matsushita K, Su G, et al. Estimated glomerular filtration rate and the risk of cancer. CJASN 2019;14: doi:10.2215/CJN.10820918.

14. Gasparini A, Evans M, Coresh J, et al. Prevalence and recognition of chronic kidney disease in Stockholm healthcare. Nephrol Dial Transplant 2016;31:2086-2094.

15. Matas AJ, Simmons RL, Kjellstrand CM, Buselmeier TJ, Najarian JS. Increased incidence of malignancy during chronic renal failure. Lancet 1975;1:883-886.

16. Birkeland SA, Storm HH, Lamm LU, et al. Cancer risk after renal transplantation in the Nordic countries, 1964-1986. Int J Cancer 1995;60:183-189.

17. Vajdic CM, McDonald SP, McCredie MR, et al. Cancer incidence before and after kidney transplantation. JAMA 2006;296:2823-2831.

18. MaisonneuveP,Agodoa L,GellertR, etal. Cancer in patients on dialysisfor endstage renal disease: an international collaborative study. Lancet 1999; 54:93.

19. Butler AM, Olshan AF, Kshirsagar AVI, Edwards JK, Nielsen ME, Wheeler SB, Brookhart MA. Cancer incidence among US Medicare ESRD patients receiving hemodialysis, 1996-2009. Am J Kidney Dis 2015;65:763.

20. Inamoto H, Ozaki R, Matsuzaki T, Wakui W, Saruta T, Osawa A. Incidence and mortality patterns of malignancy and factors affecting the risk of malignancy in dialysis patients. Nephron 1991;59:611.

21. PortFK, Ragheb NE, Schwartz AG, Hawthorne VM. Neoplasms in dialysis patients: a population-based study. Am J Kidney Dis 1989;14:119.
22. Stewart JH, Buccianti G, Agodoa L et al. Cancers of the kidney and urinary tract in patients on dialysis for end-stage renal disease: analysis of data from the United States, Europe, and Australia and New Zealand. J Am Soc Nephrol 2003; 14:197.

23. Korbet SM, WhittierWL. Management of adult minimal change disease. Clin J Am Soc Nephrol 2019; 14: doi: 10.2215/CJN.01920219.

24. Kidney Disease Improving Global Outcomes (KDIGO) Glomerulonephritis Work Group: KDIGO clinical practice guidelines for glomerulonephritis. Kidney Int 2012; Suppl 2:139-274.

25. MokY, Matsushita K, Ballew SH, Sang Y, Jung KJ, Lee S, Jee SH, Coresh J. Kidney function, proteinuria, and cancer incidence: The Korean heart study. Am J Kidney Dis 2017;70:512-521.

26. Lowrance WT, Ordonez J, Udaltsova N, Russo P, Go AS. CKD and the risk of incident cancer. J Am Soc Nephrol 2014; 25: 2327-2334.

27. Wong G, Hayen A, Chapman JR, Webster AC, Wang JJ, Mitchell P, Craig JC. Association of CKD and cancer risk in older people. J Am Soc Nephrol 2009:20:1341-1350.

28. Christensson A, Savage C, Sjoberg DD, et al. Association of cancer with moderately impaired renal function at baseline in a large, representative, population-based cohort followed for up to 30 years. Int J Cancer 2013;133:1452-1458.

29. Weng PH, Hung KY, Huang HL, Chen JH, Sung PK, Huang KC. Cancerspecific mortality in chronic kidney disease: Longitudinal follow-up of a large cohort. Clin J Am Soc Nephrol 2011;6:1121-1128.

30. Iff S, Craig JC, Turner R, Chapman JR, Wang JJ, Mitchell P, Wong G. Reduced estimated GFR and cancer mortality. Am J Kidney Dis 2014;63:23-30.

31. Wong G, Zoungas $S$, Lo S, et al. The risk of cancer in people with diabetes and chronic kidney disease. Nephrol Dial Transplant 2012;27:3337-3344.

32. Shebl FM, Warren JL, Eggers PW, Engels EA. Cancer risk among elderly persons with end-stage renal disease: A population-based case-control study. BMC Nephrol 2012;13:65.

33. Rosner MH. Cancer screening in patients undergoing maintenance dialysis: who, what, and when. AJKD 2020; doi: 10.1053/j. ajkd.2019.12.018.

34. Saran R, Robinson B, AbbottKC, et al. US Renal Data System 2018 Annual Data Report: epidemiology of kidney disease in the United States. Am J Kidney Dis. 2019;73(3)(Suppl 1):A7-A8.

35. US Renal Data System: USRDS 2004 Annual Data Report. The National Institutes of Health, National Institute of Diabetes and Digestive and Kidney Diseases, Bethesda, MD. Am J Kidney Dis 2005;5(Suppl 1):S1.

36. US Renal Data System: USRDS 2007 Annual Data Report. The National Institutes of Health, National Institute of Diabetes and Digestive and Kidney Diseases, Bethesda, MD. Am J Kidney Dis 2008;49(Suppl 1):S1.

37. Chinnadurai R, Flanagan W, Jayson GC, Kalra PA. Cancer patterns and association with mortality and renal outcomes in non-dialysis dependent chronic kidney disease: a matched cohort study. BMC Nephrol 2019;20:380-390.

38. Thompson S, James M, Wiebe N, Hemmelgarn B, Manns B, KlarenbachS, Tonelli M. Cause of death in patients with reduced kidney function. J Am Soc Nephrol. 2015; 26: 2504-2511.

39. Williams AW, Dwyer AC, Eddy AA, et al. Critical and honest conversations: the evidence behind the "Choosing Wisely" campaign recommendations by the American Society of Nephrology. Clin J Am Soc Nephrol. 2012;7(10):1664-1672.

40. Evans AJ, Cohen EJ, Cohen GF. Patterns of breast calcification in patients on renal dialysis. Clin Radiol. 1992;45(5):343-344. 